\title{
СИНТЕЗ, СТРОЕНИЕ И КООРДИНАЦИОННЫЕ СВОЙСТВА 5-ФЕНИЛ-2,3,7,8,12,18-ГЕКСАМЕТИЛ-13,17-ДИЭТИЛПОРФИНА И ЕГО 10,20-ДИНИТРОПРОИЗВОДНОГО
}

\author{
Е. М. Кувшинова, М.А. Быкова, О. В. Горнухина, И. А. Вершинина, \\ А.С. Семейкин, С.А. Сырбу
}

ЕЛИЗАВЕТА МИХАЙЛОВНА КУВШИНОВА - кандидат химических наук, дочент Ивановского государственного химико-технологического университета. Область научных интересов: физикохимические и координационные свойства порфиринов. E-mail: kuvshinovae@isuct.ru.

МАРИЯ АЛЕКСАНДРОВНА БЫКОВА - магистрант Ивановского государственного химикотехнологического университета. Область научных интересов: координационные свойства порфиринов. E-mail:kuvshinovae@isuct.ru.

ОЛЬГА ВЛАДИМИРОВНА ГОРНУХИНА - кандидат химических наук, старший научный сотрудник НИИ химии макрогетероциклических соединений Ивановского государственного химико-технологического университета. Область научных интересов: химия макрогетероциклических соединений, модификация полимерных материалов, материалымедико-биологического назначения.E-mail: ov_gor@mail.ru.

ИРИНА АЛЕКСЕЕВНА ВЕРШИНИНА - кандидат химических наук, научный сотрудник Института химии растворов им. Г. А. Крестова РАН. Область научных интересов: физико-химические свойства nорфиринов. E-mail: kuvshinovae@isuct.ru.

АЛЕКСАНДР СТАНИСЛАВОВИЧ СЕМЕЙКИН - доктор химических наук, профессор, главный научный сотрудник НИИ химии макрогетерочиклических соединений Ивановского государственного химикотехнологического университета. Область научных интересов: синтез и исследование физико-химических свойств тетрапиррольных макрогетероциклических соединений.E-mail: semeikin@isuct.ru.

СЕРГЕЙ АЛЕКСАНДРОВИЧ СЫРБУ - доктор химических наук, профессор, главный научный сотрудник Института химии растворов им. Г.А. Крестова РАН. Область научных интересов: синтез, физикохимические и координационные свойства, прикладная химия порфиринов.

153000, Россия, Иваново, пр. Шереметевский, д. 7, Ивановский государственный химико-технологический университет (ИГХТУ). тел. (4932)417855.

153000, Россия, г. Иваново, ул. Академическая, д. 1, Институт химии растворов им. Г.А. Крестова РАН (ИХР РАН).

Осущуествлен синтез 5-фенил-2,3,7,8,12,18-гексаметил-13,17-диэтилпорфирина и его динитрозамещзенного, содержащего нитрогруппь в положениях 10, 20 ядра порфирина. Структура полученных соединений доказана ЯМР, ИК, масс-спектроскопией и ЭСП. Исследована кинетика реакций образования циннковых, медных и кобальтовых комплексов синтезированных порфиринов в пиридине и уксусной кислоте. Обсуждается связь реакционной способности порфириновых лигандов с электронными эффектами нитрогрупп, эффектами пространственного искажений ядра порфина и строением сольватных оболочек солей $3 d$-металлов.

Ключевые слова: порфирин, комплексообразование, сольватокомплекс, кинетика. 


\title{
SYNTHESIS, STRUCTURE AND COORDINATION PROPERTIES OF 5-PHENYL-2,3,7,8,12,18-HEXAMETHYL-13,17- DIETHYLPORPHYRINE AND ITS 10,20-DINITRO-SUBSTITUTED
}

\author{
E. M. Kuvshinova ${ }^{a}$, M.A. Bykova ${ }^{a}$, O.V. Gornukhina ${ }^{a}$, I.A. Vershinina ${ }^{b}$, \\ A.S. Semeikina, S.A. Syrbu ${ }^{b}$ \\ a7, Sheremetevskiy Avenue, Ivanovo, 153000, Russia, Ivanovo State University of Chemistry and Technology. \\ ${ }^{b} 1$, Akademicheskaya st., Ivanovo, 153045, Russia. G.A. Krestov Institute of Solution Chemistry of the Russian \\ Academy of Sciences.
}

Carried out the synthesis of 5-phenyl-2,3,7,8,12,18-hexamethyl-13,17-diethylporphyrine and its dinitro-substituted, containing nitro group at positions 10, 20 of the porphyrine nucleus. The structure of the obtained compounds was proved by NMR, IR, mass spectroscopy and ESP. The kinetics of reactions of formation of zinc, copper and cobalt complexes of the synthesized porphyrins in pyridine and acetic acid was investigated. Te relationship between of the reactivity of porphyrin ligands electronic effects of the nitro groups, effects of the spatial distortions of the porphyrine nucleus and the structure of the solvation shells of salts of $3 d$-metals is discusse.

Key words: porphyrin, complexation, solvate complex, kinetics.

При систематическом исследовании кинетики реакций комплексообразования порфиринов с солями металлов в органических растворителях установлено, что основными факторами, влияющими на реакционную способность системы порфиринсоль являются: 1) структура тетрапиррольного макроцикла и ее отклонение от плоскостного строения [1], которое увеличивается по мере накопления объемных заместителей в мезо- и $\beta$-положениях порфина $[2-6] ; 2)$ электронные эффекты заместителей порфина $[7,8]$; 3) состав, строение и стабильность координационной сферы катиона металла $[7,9,10]$.

По сравнению с хорошо изученными планарными порфиринами непланарные тетрапиррольные аналоги характеризуются необычными физико-химическими и координационными свойствами. В связи с этим в данной работе осущест- влен синтез 5-фенил-2,3,7,8,12,18-гексаметил-13,17диэтилпорфина (1) и его 10,20-динитропроизводного (2). Структура полученных соединений доказана методами масс-спектрометрии, $\mathrm{H}^{1}$ ЯМР, ИК спектроскопии, ЭСП и квантово-химическими расчетами. Исследована кинетика реакций образования цинковых, медных и кобальтовых комплексов синтезированных порфиринов в пиридине и уксусной кислоте. Обсуждается связь реакционной способности порфиринов с электронными эффектами нитрогрупп, эффектами пространственного искажений ядра порфина и строением сольватных оболочек солей $3 d$-металлов.

\section{Экспериментальная часть}

Электронные спектры поглощения (ЭСП) порфиринов 1, 2 регистрировали на сканирую-

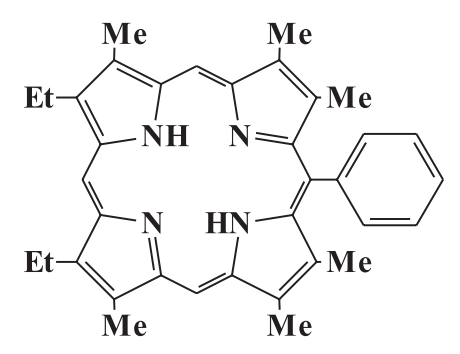

5-фенил-2,3,7,8,12,18-гексаметил-13,17диэтилпорфин (1)

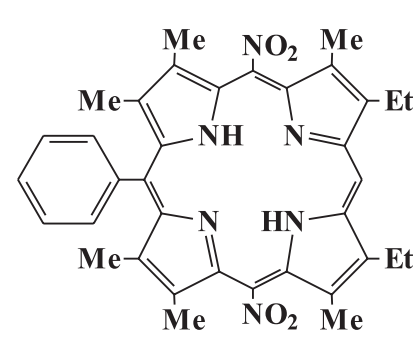

5-фенил-10,20-динитро-2,3,7,8,12,18-гексаметил13,17-диэтилпорфин (2) 
щем спектрометре Shimadzu UV-1800 в хлороформе, ИК спектры - на спектрометре Avatar 360 FT-IR в таблетках $\mathrm{KBr}$, масс-спектры - на времяпролетном масс-спектрометре Shimadzu Axima Confidence (MALDI-TOF). Спектры $\mathrm{H}^{1}$ ЯMP снимали на спектрометре Bruker 500 (внутренний стандарт ТМC). Тонкослойную хроматографию (ТCX) осуществляли на пластинах силуфола.

\section{5-фенил-2,3,7,8,12,18-гексаметил-13,17-ди- этилпорфин}

К раствору 0,6 г (2,61 ммоль) 4,4'-диметил-3,3'диэтилдипирролилметана и 0,64 г (5,22 ммоль) 2-формил-3,4-диметилпиррола в 50 мл $н$-бутанола прибавляли при перемешивании и комнатной температуре 3,0 мл конц. бромистоводородной кислоты. Смесь перемешивали при комнатной температуре 1 ч., затем добавляли 3,5 мл (34,63 ммоль) бензальдегида, нагревали до кипения и кипятили 4 ч. После охлаждения к смеси добавляли 3,0 мл $25 \%$ раствора аммиака и отфильтровывали осадок. Осадок высушивали, растворяли в хлороформе и хроматографировали на оксиде алюминия II степени активности по Брокману. Элюат упаривали и порфирин осаждали метанолом. Выход 700 мг (50,9 \%).

$R_{\mathrm{f}}$ (силуфол): 0,45 (бензол)

ЭСП $\lambda_{\text {max }}$, нм $(\lg \varepsilon): 623(3,51) ; 571(3,83) ; 536$ $(3,86) ; 502(4,15) ; 403(5,22)$ (хлороформ)

$\mathrm{H}^{1}$ ЯМР (вн. ст. ТМС) $\delta$, м.д.: $10,19 \mathrm{~s}(2 \mathrm{H}, 10,20-$ $\mathrm{H})$; 9,98s (1H, 15-H); 8,07d (2H, $J=7,4 \mathrm{~Hz}, 2,6-\mathrm{H}-\mathrm{Ph})$; $7,82 \mathrm{t}(1 \mathrm{H}, J=7,4 \mathrm{~Hz}, 4-\mathrm{H}-\mathrm{Ph}) ; 7,75 \mathrm{t}(2 \mathrm{H}, J=7,4 \mathrm{~Hz}, 3,5-$ $\mathrm{H}-\mathrm{Ph}) ; 4,09 \mathrm{q}\left(4 \mathrm{H},{ }^{1} J=7,7 \mathrm{~Hz}, 13,17-\mathrm{CH}_{2}-\mathrm{Et}\right) ; 3,67 \mathrm{~s}(6 \mathrm{H}$, $\left.12,18-\mathrm{CH}_{3}\right) ; 3,55 \mathrm{~s}\left(6 \mathrm{H}, 2,8-\mathrm{CH}_{3}\right) ; 2,47 \mathrm{~s}\left(6 \mathrm{H}, 3,7-\mathrm{CH}_{3}\right)$; $1,90 \mathrm{t}\left(6 \mathrm{H},{ }^{1} \mathrm{~J}=7,7 \mathrm{~Hz}, 13,17-\mathrm{CH}_{3}-\mathrm{Et}\right) ;-3,18 \mathrm{bs},-3,27 \mathrm{bs}$ $(2 \mathrm{H}, \mathrm{NH})\left(\mathrm{CDCl}_{3}\right)$

ИК $v$, см$^{-1}: 2961 ; 2923 ; 2863 ; 1446 ; 1264 ; 1226$; 1117; 1062; 1030; 951; 834; 751; $701(\mathrm{KBr})$

MS (MALDI-TOF) $m / z: 526,184 \max [\mathrm{M}]^{+}$вычислено: 526,728; 527,195 [M+H] $]^{+}$

5-фенил $\quad-10,20$-динитро-2,3,7,8,12,18-гексаметил-13,17-диэтилпорфин

К перемешиваемому раствору 150 мг $(0,28$ ммоль $)$ 5-фенил-2,3,7,8,12,13-гексаметил13,17 -диэтилпорфина в 5,0 мл трифторуксусной кислоты прибавляли раствор 150 мг (2,17 ммоль) нитрита натрия в 0,5 мл воды. Затем смесь выдерживали 5 суток при комнатной температуре, выливали в 50 мл воды и нейтрализовали раствором аммиака до рН 7. Осадок отфильтровывали, промывали водой, высушивали при комнатной температуре на воздухе, далее растворяли в бензоле и хроматографировали на силикагеле элюируя бензолом. Элюат упаривали и осаждали продукт метанолом. Осадок отфильтровывали, промывали метанолом и высушивали на воздухе при комнатной температуре. Выход 90 мг (52,1 \%)
$R_{\mathrm{f}}$ (силуфол): 0,54 (бензол)

ЭСП $\lambda_{\text {max }}$, нм (lge): 648 (3,57); 591 (3,87); 518 $(4,15) ; 413(5,08)$ (хлороформ)

$\mathrm{H}^{1}$ ЯМР (вн. ст. ТМС) $\delta$, м.д.: $10,06 \mathrm{~s}, 9,86 \mathrm{~s}(2 \mathrm{x} 1 \mathrm{H}$, $m s-\mathrm{H}) ; 8,10 \mathrm{~d}, 8,04 \mathrm{~d}(2 \times 2 \mathrm{H}, J=7,0 \mathrm{~Hz}, 2,6-\mathrm{H}-\mathrm{Ph}) ; 7,85 \mathrm{t}$ ( $2 \mathrm{H}, J=7,0 \mathrm{~Hz}, 4-\mathrm{H}-\mathrm{Ph}) ; 7,80 \mathrm{t}(4 \mathrm{H}, J=7,0 \mathrm{~Hz}, 3,5-\mathrm{H}-$ $\mathrm{Ph}) ; 3,88-3,97 \mathrm{~m}, 3,56-3,64 \mathrm{~m}\left(2 \times 4 \mathrm{H}, \mathrm{CH}_{2}-\mathrm{Et}\right) ; 3,52 \mathrm{~s}$, $3,38 \mathrm{~s}, 3,20 \mathrm{~s}\left(2 \times 3 \mathrm{H}+9 \mathrm{H}, 12,18-\mathrm{CH}_{3}\right) ; 3,20,3,04 \mathrm{~s}, 3,02 \mathrm{~s}$ $\left(2 \times 3 \mathrm{H}+6 \mathrm{H}, 2,8-\mathrm{CH}_{3}\right) ; 2,30 \mathrm{~s}, 2,25 \mathrm{~s}, 2,12 \mathrm{~s}(2 \times 3 \mathrm{H}+6 \mathrm{H}$, $\left.3,7-\mathrm{CH}_{3}\right) ; 1,77 \mathrm{t}, 1,56 \mathrm{t}\left(2 \times 6 \mathrm{H},{ }^{1} \mathrm{~J}=7,6 \mathrm{~Hz}, \mathrm{CH}_{3}-\mathrm{Et}\right)$; $-3,00 \mathrm{bs},-3,22 \mathrm{bs},-3,32 \mathrm{bs}(1 \mathrm{H}+2 \mathrm{H}+1 \mathrm{H}, \mathrm{NH})$

ИК $v, \mathrm{~cm}^{-1}: 2971 ; 2930 ; 2876 ; 1533 ; 1447 ; 1361$; $1158 ; 1137 ; 1058 ; 947 ; 855 ; 798 ; 705 ; 664(\mathrm{KBr})$

MS (MALDI-TOF) $m / z: 617,169[\mathrm{M}+\mathrm{H}]^{+}$, вычислено: 617,793

Ацетат цинка(II) «х.ч.», ацетат меди(II) «ч.д.а.», ацетат кобальта(II) «Х.ч.» очищали перекристаллизацией из водной уксусной кислоты и обезвоживали $\mathrm{Cu}(\mathrm{AcO})_{2}, \mathrm{Zn}(\mathrm{AcO})_{2}$ нагреванием при $370-390$ $\mathrm{K}$, а $\mathrm{Co}(\mathrm{AcO})_{2}$ - кипячением с уксусным ангидридом в течение трех часов, затем отфильтровывали, кристаллы соли промывали на фильтре гексаном и высушивали в вакуум-эксикаторе над гидроксидом калия [11].

Пиридин марки «х.ч.» обезвоживали над гидроксидом калия и дважды перегоняли с дефлегматором. Уксусную кислоту марки «х.ч.» обезвоживали дробным вымораживанием и перегоняли с дефлегматором [11]. Содержание воды в растворителях контролировали титрованием по методу Фишера [12], оно составляло не более $0,03 \%$.

Кинетику реакций координации порфиринов 1, 2 ацетатами кобальта, меди и цинка исследовали спектрофотометрическим методом на приборе Shimadzu UV-1800 в термостатируемых кюветах в интервале температур от 298 до 328 К. Колебание температуры не превышало $\pm 0,1 \mathrm{~K}$.

Реакция комплексообразования порфиринов $\mathbf{1}$, 2 с солями $\left(\mathrm{M}(\mathrm{AcO})_{2}\right)$ :

$$
\mathrm{H}_{2} \mathrm{P}+\mathrm{M}(\mathrm{AcO})_{2} \rightarrow \mathrm{MP}+2 \mathrm{AcOH}
$$

подчиняется кинетическому уравнению (2):

$$
\mathrm{d}\left[\mathrm{H}_{2} \mathrm{P}\right] / \mathrm{dt}=-\mathrm{k}\left[\mathrm{H}_{2} \mathrm{P}\right] \cdot\left[\mathrm{M}(\mathrm{AcO})_{2}\right]^{\mathrm{n}},
$$

где $\mathrm{H}_{2} \mathrm{P}$ - порфирин, МР - металлопорфирин, $k-$ константа скорости реакции (1). Образование цинковых, медных и кобальтовых комплексов исследуемых порфиринов имеет первый кинетический порядок по лиганду, что доказывают линейные зависимости в координатах $\lg \left(c_{\mathrm{H}_{2} \mathrm{P}}^{0} / c_{\mathrm{H}_{2} \mathrm{P}}\right)-t$, где $c_{\mathrm{H}_{2} \mathrm{P}}^{0}$ и $c_{\mathrm{H}_{\mathrm{P}} \mathrm{P}}$ начальная и текущая концентрация порфирина соответственно. Кинетические опыты проводили в условиях $\sim$ стократного избытка ацетатов 
металлов по отношению к порфирину, что позволило рассчитать эффективные константы $\left(k_{э ф}\right)$ peакции (1) по уравнению (3).

$$
k_{э \phi}=(1 / t) \cdot \ln \left[\left(A_{o}-A_{\infty}\right) /\left(A-A_{\infty}\right)\right]
$$

Здесь $A_{o}, A, A_{\infty}-$ оптические плотности раствора в начальный момент, в момент времени $t$ и по окончании реакции соответственно.

Константы скорости $k_{n+1}$ рассчитывали по уравнению (4).

$$
k_{n+1}=k_{\ni \phi} / c^{n}{ }_{M e(A c O)},
$$

где $n$ порядок реакции по соли.

Установлено, что порядок реакции по ацетату меди в уксусной кислоте равен 0,5 , что согласуется с данными [13] и объясняется высокой степенью димеризации соли, $K_{\text {дим }}>10^{6}$. Димерная форма соли $\left[\mathrm{Cu}_{2}(\mathrm{AcO})_{4}(\mathrm{AcOH})_{2}\right]$ кинетически инертна, и с порфиринами реагирует только мономерный сольватокомплекс $\left[\mathrm{Cu}(\mathrm{AcO})_{2}(\mathrm{AcOH})_{4}\right]$. В пиридине на процесс димеризации накладывается ионизация соли с образованием относительно небольшого количества высокоактивного сольватокомплекса $\left[\mathrm{Cu}(\mathrm{AcO})(\mathrm{Py})_{5}\right]^{+}$. В результате кинетический порядок реакции по соли уменьшается до 0,4 [13]. К сожалению, константы равновесия выше упомянутых реакций не определены, что не позволяет рассчитать величины энтропии реакций координации порфиринов ацетатом меди. Порядок реакции по $\mathrm{Co}(\mathrm{AcO})_{2}, \mathrm{Zn}(\mathrm{AcO})_{2}$ в пиридине и в уксусной кислоте равен 1 [13]. Эти соли в растворах существуют в единственной форме сольватокомплексов $\left[\mathrm{M}(\mathrm{AcO})_{2}(\mathrm{Solv})_{4}\right]$.

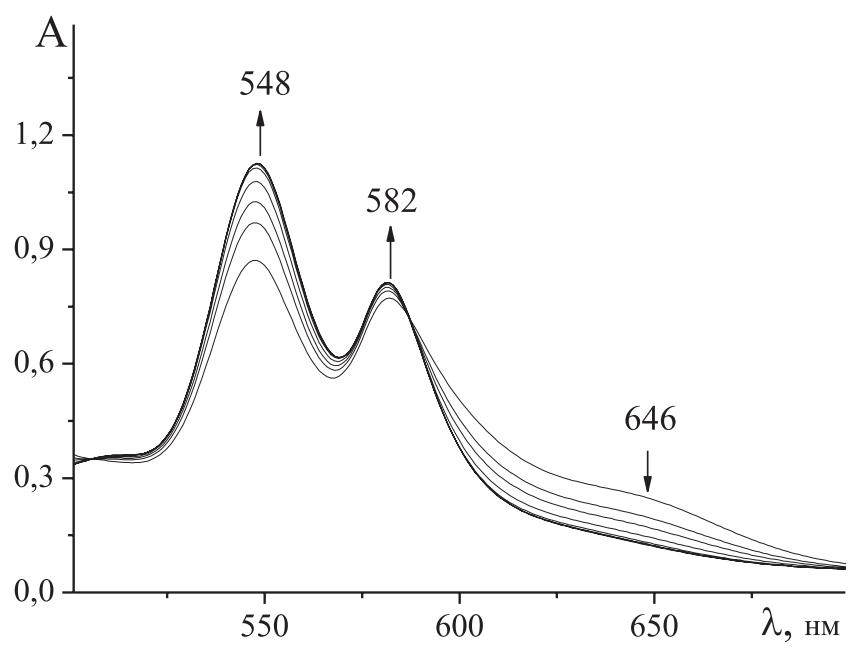

Рис. 1 Изменение спектров поглощения при комплексообразовании $2 \mathrm{c} \mathrm{Zn(Ac)}{ }_{2}$ в уксусной кислоте
Энергию активации реакций образования металлопорфиринов рассчитывали, исходя из уравнения Аррениуса (5).

$$
k=A \cdot e^{-E / R T}
$$

Предэкспоненциальный множитель (A) рассчитывали по уравнению (6)

$$
\ln A=\ln k_{1+\mathrm{n}}+E / R T
$$

В спектрах всех реагирующих систем наблюдались четкие изобестические точки (рис. 1,2 ).

В ходе каждого опыта проводили 15-25 замеров оптической плотности раствора через определенные промежутки времени на аналитической длине волны, на которой ЭСП лиганда и комплекса сильно различаются. Средняя квадратичная погрешность определения эффективных констант скорости $\left(k_{\text {эф }}\right)$ составляла не более $5 \%$. Эффективные константы скорости и кинетические параметры реакций образования цинковых, медных и кобальтовых комплексов порфиринов 1, 2 представлены в табл. 1, 2.

\section{Обсуждение результатов}

5-Фенил-2,3,7,8,12,18-гексаметил-13,17-диэтилпорфин $\mathbf{1}$ получен одноколбовой кислотной конденсацией 2-формил-3,4-диметилпиррола с $\quad 3,3$ '-диэтил-4,4'-диметилдипирролилметаном с последующей циклизацией промежуточного биладиена по реакции с бензальдегидом и окислением образующегося порфириногена без его выделения [14, 15] (Схема 1).

Наличие в составе 1 двух этильных заместителей обеспечивает высокую растворимость порфи-

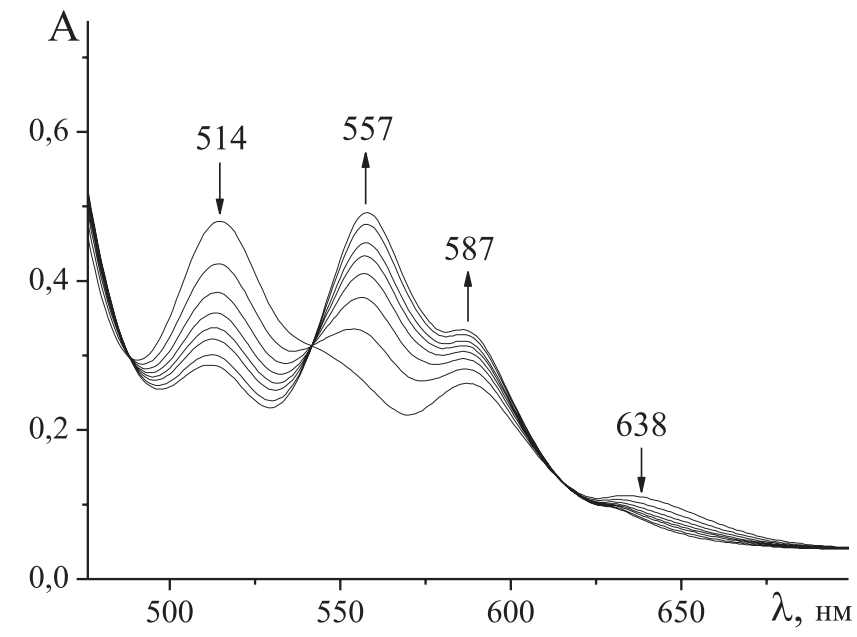

Рис. 2 Изменение спектров поглощения при комплексообразовании 2 с $\operatorname{Zn}(\mathrm{Ac})_{2}$ в пиридине 
<smiles>CCc1c(C)c[nH]c1Cc1[nH]cc(C)c1CC</smiles>

Схема 1
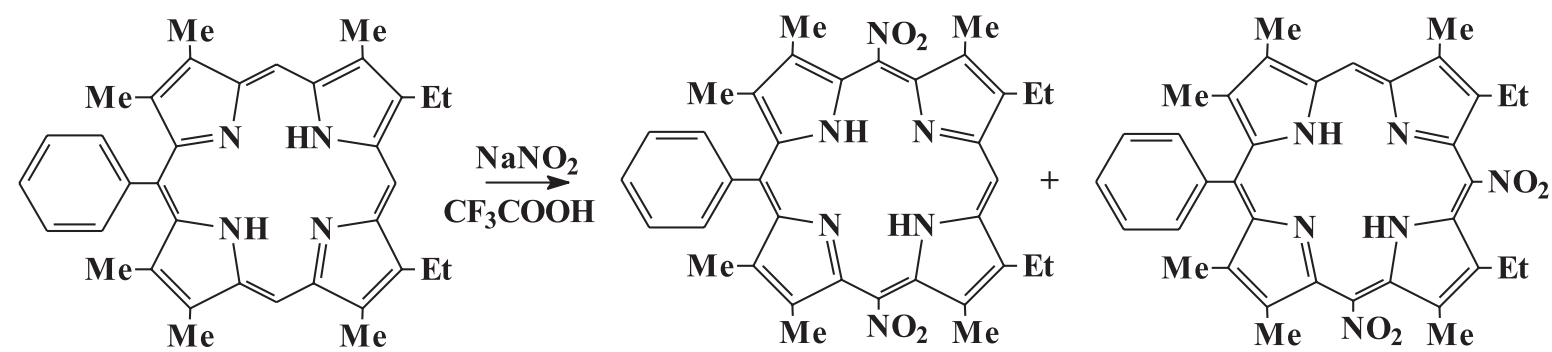

Схема 2

рина, достаточную для последующего его нитрования. Смесь 10,20- и 10,15-динитрофенил-5-фенил$2,3,7,8,12,18$-гексаметил-13,17-диэтилпорфинов синтезировали по видоизмененной методике [12, 16] нитрованием 5-фенил-2,3,7,8,12,18-гексаметил13,17-диэтилпорфина нитритом натрия в трифторуксусной кислоте и разделяли хроматографией на силикагеле с бензолом в качестве проявителя (Схема 2).

Судя по спектральным характеристикам порфирин 2, его тетрапиррольное ядро, сильно деформирован. Это проявляется в сильном батохромном сдвиге всех полос поглощения в ЭСП при переходе от 1 к 2: 623, 571, 536, 502, 403 и 648, 591, 518, 413 (хлороформ). Такое смещение максимумов полос типично для непланарных порфиринов [1]. Деформация макроцикла $\mathbf{2}$ снижает его ароматичность и, соответственно, наблюдается слабопольный сдвиг сигналов мезо-атомов и атомов метильных групп 2 по сравнению с 1 (см. выше).

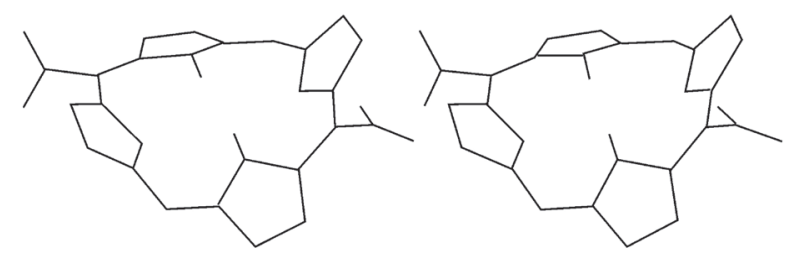

Рис. 3. Стереоизображение ядра молекулы 5-фенил10,20 -динитрофенил- $2,3,7,8,12,18$-гексаметил-13,17диэтилпорфина
Расчеты методом РМ3 показали, что ароматическое тетрапиррольное ядро порфирина 1 плоское. Введение нитрогрупп в положения 10, 20 ведет к существенной деформации макроцикла из-за стерического отталкивания нитрогрупп с соседними метильными заместителями. Рис. 3 демонстрирует характер искажения ядра молекулы, приобретающего рифленую структуру, одну из типичных для непланарных порфиринов [1-4].

С целью изучения реакционной способности полученных порфиринов измерена кинетика координации их ацетатами цинка, меди и кобальта в кислотном растворителе - уксусной кислоте и в основном - пиридине (табл. 1, 2).

Данные табл. 1, 2 показывают, что в пиридине скорость реакции комплексообразования порфирина 2 с $\mathrm{Cu}(\mathrm{AcO})_{2}, \mathrm{Zn}(\mathrm{AcO})_{2}$ и $\mathrm{Co}(\mathrm{AcO})_{2}$, по крайней мере, на три порядка выше, чем с порфирином 1. При этом $E_{\text {а }}$ снижается в полтора - два раза и существенно возрастает величина предэкспоненциального множителя $A$. Это обусловлено наложением двух факторов: структурного и электронного.

Нитрогруппы располагаются, практически, перпендикулярно по отношению к соседним фрагментам макроцикла, торсионные углы фрагментов C-C-N-O составляют примерно 80. Таким образом, электронное влияние групп $\mathrm{NO}_{2}$ сводится к отрицательному индукционному эффекту, и, следовательно, основной вклад в резкое изменение реакционной способности порфиринов при переходе 
Эффективные константы скорости координации порфиринов 1, 2 ацетатами меди, цинка, кобальта в уксусной кислоте и пиридине

\begin{tabular}{|c|c|c|c|c|c|c|c|c|}
\hline \multirow[b]{2}{*}{ Соль } & \multicolumn{4}{|c|}{1} & \multicolumn{4}{|c|}{2} \\
\hline & $\begin{array}{c}c \cdot 10^{3}, \\
\text { моль/л }\end{array}$ & $\begin{array}{l}\lambda * \\
\text { Hм }\end{array}$ & $\begin{array}{l}T, \\
\mathbf{K}\end{array}$ & $\begin{array}{c}k_{э \phi} \cdot 10^{3} \\
\mathbf{c}^{-1}\end{array}$ & $\begin{array}{c}c \cdot 10^{3}, \\
\text { моль/л }\end{array}$ & $\begin{array}{c}\lambda, \\
\mathbf{H M}\end{array}$ & $\begin{array}{l}T, \\
\mathbf{K}\end{array}$ & $\begin{array}{c}k_{э \phi} \cdot 10^{3} \\
\mathrm{c}^{-1}\end{array}$ \\
\hline \multicolumn{9}{|c|}{ В уксусной кислоте } \\
\hline $\mathrm{CuAc}_{2}$ & Реакі & завер & ся при & нии растворов & 1,96 & 538 & $\begin{array}{l}288 \\
298 \\
308\end{array}$ & $\begin{array}{c}30,0 \pm 1,4 \\
58 \pm 3 \\
115 \pm 5\end{array}$ \\
\hline $\mathrm{ZnAc}_{2}$ & Реакı & завер & ся прг & нии растворов & 2,02 & 548 & $\begin{array}{l}289 \\
298 \\
308 \\
\end{array}$ & $\begin{array}{c}32,0 \pm 1,3 \\
67 \pm 3 \\
140 \pm 6\end{array}$ \\
\hline $\mathrm{CoAc}_{2}$ & 1,72 & 532 & $\begin{array}{l}298 \\
308 \\
318\end{array}$ & $\begin{array}{c}0,167 \pm 0,004 \\
0,69 \pm 0,03 \\
2,52 \pm 0,13\end{array}$ & 1,72 & 592 & $\begin{array}{l}298 \\
308 \\
318\end{array}$ & $\begin{array}{c}1,53 \pm 0,07 \\
3,24 \pm 0,15 \\
6,6 \pm 0,3\end{array}$ \\
\hline \multicolumn{9}{|c|}{ В пиридине } \\
\hline & & & 1 & & & & 2 & \\
\hline $\mathrm{CuAc}_{2}$ & 4,9 & 502 & $\begin{array}{l}308 \\
318 \\
328\end{array}$ & $\begin{array}{c}0,019 \pm 0,0007 \\
0,035 \pm 0,0016 \\
0,062 \pm 0,005\end{array}$ & 1,23 & 551 & $\begin{array}{l}288 \\
298 \\
308\end{array}$ & $\begin{array}{c}30,50 \pm 1,20 \\
51,0 \pm 2,00 \\
83,0 \pm 3,00\end{array}$ \\
\hline $\mathrm{ZnAc}_{2}$ & 5,20 & 503 & $\begin{array}{l}308 \\
318 \\
328\end{array}$ & $\begin{array}{c}0,034 \pm 0,0013 \\
0,088 \pm 0,002 \\
0,22 \pm 0,004\end{array}$ & 5,2 & 515 & $\begin{array}{l}298 \\
308 \\
318\end{array}$ & $\begin{array}{l}4,84 \pm 0,19 \\
8,20 \pm 0,30 \\
13,0 \pm 0,52\end{array}$ \\
\hline $\mathrm{CoAc}_{2}$ & Реак & не за & ается & ние трёх суток & 5,50 & 513 & $\begin{array}{l}298 \\
308 \\
318\end{array}$ & $\begin{array}{l}0,30 \pm 0,014 \\
0,70 \pm 0,032 \\
1,50 \pm 0,068\end{array}$ \\
\hline
\end{tabular}

* $\lambda$ - аналитическая длина волны

$* \lambda$ - analytical wavelength

Таблииа 2

Кинетические параметры реакции координации порфиринов 1,2 ацетатами меди, цинка, кобальта в уксусной кислоте и пиридине

\begin{tabular}{|c|c|c|c|c|c|c|}
\hline \multirow[b]{2}{*}{ Соль } & \multicolumn{3}{|c|}{1} & \multicolumn{3}{|c|}{2} \\
\hline & $\begin{array}{c}k_{\mathrm{n}+1}{ }^{308}, \\
\text { Л/(моль·с) }\end{array}$ & $\begin{array}{c}E_{\mathrm{a}}, \\
\text { кДж/моль }\end{array}$ & $\begin{array}{l}A, \\
\mathbf{c}^{-1}\end{array}$ & $\begin{array}{c}k_{\mathrm{n}+1}{ }^{308}, \\
\text { Л/(Моль·с) }\end{array}$ & $\begin{array}{c}E_{\mathrm{a}}, \\
\text { кДж/моль }\end{array}$ & $\begin{array}{l}A, \\
\mathrm{c}^{-1}\end{array}$ \\
\hline \multicolumn{7}{|c|}{ В уксусной кислоте } \\
\hline $\mathrm{CuAc}_{2}$ & \multicolumn{3}{|c|}{ Реакция завершается при сливании растворов } & $2,59 \pm 0,11$ & $52,0 \pm 1,1$ & $1,79 \cdot 10^{9}$ \\
\hline $\mathrm{ZnAc}_{2}$ & \multicolumn{3}{|c|}{ Реакция завершается при сливании растворов } & $3,12 \pm 0,14$ & $57,0 \pm 1,0$ & $1,46 \cdot 10^{10}$ \\
\hline $\mathrm{CoAc}_{2}$ & $0,40 \pm 0,02$ & $106,3 \pm 1,5$ & $4,4 \cdot 10^{17}$ & $1,91 \pm 0,08$ & $58,0 \pm 1,3$ & $1,37 \cdot 10^{10}$ \\
\hline \multicolumn{7}{|c|}{ В пиридине } \\
\hline $\mathrm{CuAc}_{2}$ & $(72 \pm 3) \cdot 10^{-3}$ & $51,2 \pm 1,5$ & $7,6 \cdot 10^{4}$ & $1,21 \pm 0,05$ & $36,8 \pm 1,3$ & $2,12 \cdot 10^{6}$ \\
\hline $\mathrm{ZnAc}_{2}$ & $(169 \pm 4) \cdot 10^{-4}$ & $78,3 \pm 1,0$ & $1,3 \cdot 10^{11}$ & $1,58 \pm 0,06$ & $39,0 \pm 1,1$ & $6,67 \cdot 10^{6}$ \\
\hline $\mathrm{CoAc}_{2}$ & \multicolumn{3}{|c|}{ Реакция не завершается в течение трёх суток } & $0,130 \pm 0,005$ & $63,0 \pm 1,4$ & $6,4 \cdot 10^{9}$ \\
\hline
\end{tabular}


от 1 к 2 следует отнести к структурному фактору деформации ядра молекулы.

В работе [7] установлено, что переходное состояние реагирующей системы соль-порфирин при комплексообразовании сольватокомплексов типа $\left[\mathrm{MX}_{2}(\text { Solv })_{4}\right]$ достигается при отрыве двух молекул Solv и существенном растяжении связей N-H порфирина. При этом нарождаются связи катиона металла с третичными атомами азота порфирина (рис. 4). В зависимости от природы растворителя один или оба ацидолиганда X могут быть замещены молекулярными лигандами - молекулами растворителя. Необычно, но вполне закономерно то, что деформация макроцикла порфиринов приводит одновременно и к увеличению их основности, и к росту кислотных свойств [17]. В связи с этим становятся понятными причины резкого ускорения реакции комплексообразования в электронодонорных растворителях при переходе от плоских к деформированным порфиринам.

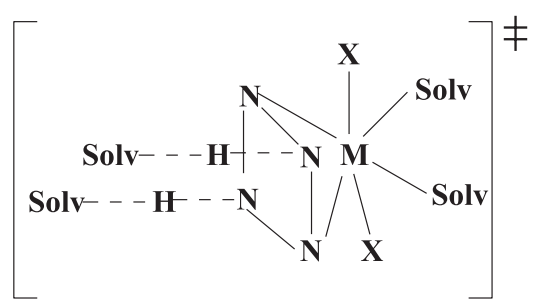

Рис. 4. Переходное состояние реагирующей системы порфирин - октаэдрический сольватокомплекс катиона металла

Вместе с тем, очевидны причины резкого замедления реакции при переходе от 1 к 2 в уксуснокислых растворах. Молекулы уксусной кислоты образуют прочные водородные связи с третичными атомами азота порфирина 2 и существенно затрудняют контакт сольватокомплексов металлов к координационному центру порфирина рис. 1, 2 .

Порядок реакции по ацетату меди в уксусной кислоте равен 0,5 , что согласуется с данными [18] и объясняется высокой степенью димеризации соли $K_{\text {дим }}>10^{6}$. Димерная форма соли $\left[\mathrm{Cu}_{2}(\mathrm{AcO})_{4}(\mathrm{AcOH})_{2}\right]$ кинетически инертна, и с порфиринами реагирует только мономерный сольватокомплекс $\left[\mathrm{Cu}(\mathrm{AcO})_{2}(\mathrm{AcOH})_{4}\right]$. В пиридине на процесс димеризации накладывается ионизация соли с образованием, по-видимому, незначительной доли высокоактивного сольватокомплекca $\left[\mathrm{Cu}(\mathrm{AcO})(\mathrm{Py})_{5}\right]^{+}$. В результате кинетический порядок реакции по соли уменьшается до 0,4 [13]. К сожалению, константы равновесия выше упо- мянутых реакций не определены, что не позволяет рассчитать величины энтропии реакций координации порфиринов ацетатом меди. Порядок реакции по $\mathrm{Co}(\mathrm{AcO})_{2}, \mathrm{Zn}(\mathrm{AcO})_{2}$ в пиридине и в уксусной кислоте равен 1. Эти соли в растворах существуют в единственной форме сольватокомплексов $\left[\mathrm{M}(\mathrm{AcO})_{2}(\mathrm{Solv})_{4}\right][13]$.

В зависимости от природы катиона соли скорость реакции комплексообразования порфиринов $\mathbf{1 , 2}$ в пиридине и уксусной кислоте растет в ряду $\mathrm{Co}<\mathrm{Zn}<\mathrm{Cu}$. Несмотря на высокую степень димеризации ацетата меди, реакция образования комплексов меди протекает быстрее, чем комплексов цинка и кобальта. Объяснением этому является проявление эффекта Яна-Теллера, благодаря которому сольватокомплексы меди(II) имеют конфигурацию координационной сферы с двумя существенно растянутыми и ослабленными связями $\mathrm{M}-\mathrm{AcOH}$.

Минимальная скорость комплексообразования наблюдается в реакции с ацетатом кобальта, сольватокомплекс которого $\left.\left[\mathrm{Co}(\mathrm{AcO})_{2}(\mathrm{AcOH})_{4}\right)\right]$ наиболее стабилен среди исследованных [13].

Исследования проведень с использованием ресурсов Центра коллективного пользования научным оборудованием ФГБОУ ВО «ИГХТУ» и Центра коллективного пользования научным оборудованием «Верхневолжский региональный центр физикохимических исследований» ИХР РАН.

Работа выполнена в рамках государственного задания проект № 4.7305.2017/8.9.

\section{Литература}

1. Голубчиков О.А., Пуховская С.Г., Кувиинова Е.М. Успехи химии. 2005. Т. 74. No 3. С. 268-284. (Golubchikov O.A., Pukhovskaya S.G., Kuvshinova E.M. Russ. Chem. Ev. 2005. V. 74. No3. P. 249-264) DOI:10.1070/ RC2005v074n03ABEH000925.

2. Senge M.O. Chem. Commun. 2006. No 3. P. 243-256.

3. Barkigia K.M., Renner M.W., Senge M.O., Fajer J. J. Phys. Chem. B. 2004. 108 (7). P. 2173-2180. DOI: 10.1021/jp036398d.

4. Retsek J.L., Medforth C.J., Nurco D.J., Gentemann S., Chirvony V.S., Smith K.M., Holten D. J. Phys. Chem. B. 2001. 105 (27). P. 6396-6411. DOI: 10.1021/ jp004556k.

5. Ефимович В.А., Пуховская С.Г., Голубчиков О.А. Ж. Неорганической химии. 2013. Т. 58. № 4. С. 467-472. (S. G. Pukhovskaya, V. A. Efimovich, and O. A. Golubchikov. Russian Journal of Inorganic Chemistry. 2013. V. 58. No 4. P. 406-410).

6. E.M. Kuvshinova, I.A. Vershinina, S.A. Syrbu, O.A. Golubchikov. Russian Journal of General Chemis- 
try. 2017. V. 87. No 9. P. 2181-2187. DOI: 10.1134/ S1070363217090444.

7. Кувиинова Е.М., Семейкин А.С., Голубчиков О.А. Журн. физ. химии. 1997. Т. 71. №3. С. 440-442.

8. Березин Б.Д. Координационные соединения порфиринов и фталоцианина. М.: Наука, 1978. $280 \mathrm{c}$.

9. Голубчиков О.А. Березин Б.Д. Журн. физ. химии. 1986. Т. 60. Вып. 9. С. 2113-2126.

10. Кувшинова Е.М., Пуховская С.Г., Голубчиков О.А., Березин Б.Д. Журн. координ. химии. 1993. Т. 19. № 8. С. 630-632.

11. Гордон А., Форд Р. Спутник химика. М.: Мир. 1976. C. 541.

12. Денеш И. Титрование в неводных средах. М.: Мир. 1971. С. 13.

13. Березин Б.Д., Голубчиков О.А. Координационная химия сольватокомплексов солей переходных металлов. М.: Наука. 1992. 234 с.
14. Kolodina E.A., Lubimova T.V., Syrbu S.A., Semeikin A.S. Macroheterocycles. 2009. V. 2. No 1. P. 33-41. DOI: MHC2009 t02n01 33-41.pdf.

15. Колодина Е.А., Сырбу С.А., Семейкин А.С., Койфман О.И. ЖОрХ. 2010. Т. 46. Вып. 1. С. 136-141. (Е.A. Kolodina, S.A. Syrbu, A.S. Semeikin, and O.I. Koifman. Russian Journal of Organic Chemistry. 2010. V. 46. No 1. P. 138-143). DOI:10.1134/S107042801001015X.

16. Lyubimtsev A., Syrbu S., Zheglova N., Semeikin A., Koifman O. Macroheterocycles. 2011. V. 4. No4. P. 265-269. DOI: 10.6060/mhc2011.4.05.

17. Березин Д.Б. Макроциклический эффект и структурная химия порфиринов. М.: Красанд. 2010, 424 с.

18. Кувшинова Е.М., Пуховская С.Г., Семейкин А.С., Голубчиков О.А. ЖОХ. 2004. Т. 74. Вып. 10. С. 17331738. (E.M. Kuvshinova, S.G. Pukhovskaya, A.S. Semeikin, and O.A. Golubchikov. Russian Journal of General Chemistry. V. 74. No 10. 2004. P. 16101615). DOI: $10.1007 / \mathrm{s} 11176-005-0066-8$. 